The Suspension of the Gold Standard as Sustainable Monetary Policy

Elisa Newby

December 2008

CWPE 0856 


\title{
The Suspension of the Gold Standard as Sustainable
}

\section{Monetary Policy*}

\author{
Elisa Newby ${ }^{\dagger}$ \\ University of Cambridge
}

29 June 2009

\begin{abstract}
This paper models the gold standard as a state contingent commitment technology that is only feasible during peace. Monetary policy during war, when the gold convertibility rule is suspended, can still be credible, if the policy maker's plan is to resume the gold standard in the future. The DGE model developed in this paper suggests that the resumption of the gold standard was a sustainable plan, which replaced the gold standard as a commitment technology and made monetary policy time consistent. Trigger strategies support the equilibrium: private agents retaliate if a policy maker defaults its plan to resume the gold standard.
\end{abstract}

Jel Classification: C61, E31, E4, E5, N13

Key words: Time consistency, Monetary policy, Monetary regimes

*Acknowledgements: I thank Michael Bordo, Max Gillman, Charles Nolan and Gary Shea for helpful comments. I acknowledge the financial support of the Centre for Dynamic Macroeconomic Analysis (University of St Andrews) and Yrjö Jahnsson Foundation.

${ }^{\dagger}$ Fitzwilliam College, University of Cambridge, Cambridge, CB3 0DG, UK. Tel: +44 (0) 1223477098. E-mail: emsn2@cam.ac.uk 


\section{Introduction}

Traditionally the gold standard has been modelled as an automatic and impersonal monetary system, 'golden fetters', which restricted sovereigns' power over economic policy. The gold standard rule obligated each central bank to maintain the value of the national paper currency in terms of a fixed weight of gold by buying and selling gold at a fixed price on demand. The convertibility rule and reserves set a limit to the money supply and guaranteed almost zero inflation. ${ }^{1}$ Yet, if we expand our focus from the relatively short-lived International Classical Gold Standard of 1880-1914 to a wider time horizon, the gold standard and other commodity standards do not emerge as such disciplinarian rules. According to the surveys by Bordo and Kydland (1995, 1996) and Bordo and Schwartz (1997) 21 countries defaulted on the convertibility rule on 38 occasions before World War II. For example, the commodity standard was suspended in France during the French Revolution, in England from 1797-1821 during the French Wars, in the US from 1862-1878 during the Civil War and in several countries during the First World War.

Instead of a monotonic policy rule, this paper considers the gold standard as a commitment mechanism that restricted monetary policy during normal times, but which became unfeasible during major wars and crises. Because monetary authorities were able to decide how much inconvertible fiduciary money to issue during the suspension periods, they were predecessors of the modern fiat money system. But compared with the hyperinflationary paper money experiments of the twentieth century, suspensions were relatively successful: in 24 out of 38 cases the gold standard was resumed without devaluations and the inconvertible paper money remained in circulation during the suspension.

According to Bordo et al monetary policy under the suspensions was credible, because the gold standard was a contingent rule: during a wartime emergency, when the govern-

\footnotetext{
${ }^{1}$ See calculations by Santoni (1984).
} 
ment needed to collect seigniorage revenue, the gold standard rule could be abandoned temporarily on the understanding that after the emergency had passed safely convertibility would be restored at original parity. Along the lines of this theory, agents considered the gold standard and the suspension to be essentially the same monetary system and could not think of any feasible alternatives to gold: 'Thus, when an emergency occurred, the abandonment of the standard would be viewed by all to be a temporary event since, from their [the public's] experience, only gold or gold-backed claims truly served as money.' ${ }^{2}$

My interpretation of contingency differs from that of Bordo et al in that I assume the resumption of the gold standard to be endogenous, not exogenous. I chose this alternative approach because it is supported by historical evidence: firstly, the resumption date was unknown during the suspensions or policy makers moved previously agreed resumption date forward; and secondly, on several occasions the return to the gold standard created strong political opposition. In this paper the bad state, 'war', is unexpected, and can lead to two potential defaults. The first default is what Grossman and Van Huyck (1988) call excusable and it occurs when the authority is forced to abandon the commitment technology, the gold standard, upon arrival of the bad state. The second potential default follows the monetary authority's decision not to resume the original gold convertibility rule even though the state of the world has switched back to the good state. This default is total and unjustified, and leads to the loss of the monetary authority's reputation. But if the resumption of the commitment rule involves incurring a cost, as in this model, the authority might not have an incentive to resume the rule. A key objective of the model is to define conditions which ensure that the second default does not occur and the gold convertibility rule is resumed.

In this paper I evaluate the question of what makes monetary policy credible and time

\footnotetext{
${ }^{2}$ Bordo and Kydland (1995).
} 
consistent in the absence of the commitment mechanism - the gold standard. To avoid getting entangled with the historical details of various suspension periods, I develop a dynamic general equilibrium model of the gold standard and the suspension, and use it to analyze the extent by which the gold standard functions as a contingent rule. The model demonstrates that the gold standard with a fixed gold reserve ratio is a commitment technology that solves the economy's time inconsistency problem in the conduct of monetary policy if the economy has nominal rigidities, but the suspension of the gold standard subsequently reveals the problem. Because the money base under the suspension is not fixed to the existing gold reserve, the central bank, in the presence of sticky wages, has an opportunity to expand output and yield seigniorage to the government by issuing inconvertible paper money. I conduct the analysis within the cash-in-advance model, which, by emphasizing the paper money as a medium of exchange, describes the role of paper money in those relatively developed economies that suspended the convertibility rule.

As suspension periods often lasted several years, even decades, the policy maker and the public had time to interact, and, therefore, my model emphasizes the paramount role of the public's expectations and policy maker's reputation in making the suspension a credible regime. Following Chari and Kehoe (1990), the model adapts Abreau's (1988) optimal penal codes under discounting to policy games played between a benevolent government and private sector. The sustainable policy plan during the suspension - to resume the gold standard at the old par value in the future - is supported by a reputational equilibrium in which private expectations display an extreme form of trigger-like behavior: a single deviation by the central bank from its announced plan to resume the gold standard causes the economy to revert permanently to its worst possible outcome, which, in this commodity standard setup, I call a commodity money. If compared with the gold standard, the commodity money regime, where only gold coins circulate as a medium of 
exchange, is inefficient and reduces welfare. The gold standard is resumed if the incentive compatibility constraint is satisfied: the discounted net utility of the adjustment and the gold standard has to be larger or equal to the discounted net utility of default and the commodity money thereafter.

My theoretical analysis produces three main results. Firstly, the suspension is a credible regime, because the resumption of the gold standard at the original par value is a sustainable plan. The central bank's plan to resume the gold standard at some future point replaces the gold standard as a reputational device, which limits discretionary money creation and solves the time inconsistency problem. Secondly, the model explains why the central bank resumes the gold standard although the suspension, by increasing a degree of flexibility in the economy, proves to be a relatively successful regime. The gold standard is resumed, because it maximizes social welfare in the long-run as during normal times the central bank cannot conduct time consistent monetary policy without commitment technology. Finally, sustainability of the resumption plan is of vital importance to the economy during war. Private agents accept paper money as a medium of exchange because they believe that in the future paper money would again be convertible. Sustainability of wartime monetary policy enables the central bank to (i) stabilize output and consumption through private discount policy; (ii) derive seigniorage revenue to the government through public discount policy and (iii) postpone the welfare reducing adjustment to peacetime.

Despite the long-standing interest of economists in the suspensions, only a handful of open market models exist, and the suspension has not been modelled in the general equilibrium, or a credibility and time inconsistency framework. Although many aspects of my model are in the tradition of the relatively recently published classical models on a commodity money standard proposed by Barro (1979), Sargent and Wallace (1983), 
Goodfriend (1988), Velde and Weber (2000) and Bordo et al. (2003), the fundamental difference is that I model the gold standard as an endogenous domestic monetary policy rule, not as a exogenous fixed monetary constitution or as a fixed exchange rate system. The model is not a complete presentation of the economic policy under the suspension, and I focus on monetary policy and theory. Neither do I model some specific historical period but describe a new framework which includes key elements of the suspension.

The paper proceeds as follows. In Section II, I present the baseline model, which, by changing the values of key parameters, I use to analyze monetary policy under the gold standard and the suspension. In Section III, I characterize the sustainability of the resumption plan and develop some numerical examples. The final section acts as a conclusion to the foregoing.

\section{A Dynamic General Equilibrium Model of the Gold Standard and the Suspension}

The analysis requires the development of a new theoretical model in which the gold standard rule can be suspended and in which the gold standard operates as a domestic rather than an international monetary policy rule. The gold standard is a commitment technology, which, as in Chari and Kehoe (1990) and Ireland (1997), is sustainable by definition and solves the economy's time inconsistency problem. Four key elements of the model are (i) nominal wages are sticky; (ii) the paper money has value only if private agents are able to convert it to gold instantly or at some future point; (iii) the central bank functions also as a financial intermediate and issues unbacked paper money through discounting; and, (iv) the suspension of the gold standard is exogenous in the bad state of the world, but the resumption of the gold standard is not exogenous when the economy is 
again in the good state of the world. In particular, (i) and (iii) are supported by historical evidence. $^{3}$

\subsection{A Cash-in-Advance Economy}

Consider an economy in which the private sector consists of a large number of identical households and firms, and the public sector of a central bank and a government. Since households and firms behave as atomistic competitors, the discussion is restricted to a representative agent of each type. To start with, let us assume that the central bank follows the gold standard rule by being prepared to buy or sell gold in exchange for paper currency with the fixed conversion rate $Q$, but without committing to keep the ratio between its gold reserve and money supply constant. Following Ricardo (1821), money supply $M_{t}^{s}$ is backed by the monetary gold $A_{t}^{g}$

$$
M_{t}^{s}=\frac{Q A_{t}^{g}}{\eta_{t}}
$$

The gold reserve ratio, which defines the proportion of the circulating paper money stock that is backed by monetary gold, is denoted by $\eta_{t} \in(0,1]$.

The representative household consumes two goods: perishable consumption good $C_{t}$ and gold $A_{t+1}$ which depreciates at constant rate of $(1-\delta)$. The household enters period $t$ with depreciated gold $\delta A_{t}$ which is measured in ounces. The household is then endowed with fixed amount $A^{s}$ of new gold, and next, it chooses what proportion of its gold holdings $\delta A_{t}+A^{s}$ is minted to specie, deposited at the central bank in exchange for paper currency

\footnotetext{
${ }^{3}$ Lindert and Williamson (1984) and Hanes (1993) suggest that nominal wages were sticky in England and the US in the $18^{\text {th }}$ and $19^{\text {th }}$ centuries. Duffy (1982) shows that the Bank of England was an active financial intermediary from 1797-1821. Alternatively, as in Carlstrom and Fuerst (1995), private banks could act as an intermediary, to whom the central bank forwards monetary transfers, but the former approach was chosen for simplicity.
} 
and transferred to the next period:

$$
\delta A_{t}+A^{s}-\left(S_{t+1}^{s}-S_{t}^{s}\right)-\left(A_{t+1}^{g}-A_{t}^{g}\right)=A_{t+1} .
$$

In $(2)\left(S_{t+1}^{s}-S_{t}^{s}\right)$ is the change in period $t$ specie stock, and $\left(A_{t+1}^{g}-A_{t}^{g}\right)$ the change in the central bank's gold reserve. The equation (2) can be expressed in terms of growth rates and gold backing by defining the growth rate of specie supply as $z_{t}=S_{t+1}^{s} / S_{t}^{s}$ and the rate of monetary expansion proportional to monetary gold as $x_{t}=A_{t+1}^{g} / A_{t}^{g}$, writing (1) in terms of $A_{t}^{g}$ and substituting these into (2):

$$
Q \delta A_{t}+Q A^{s}-Q\left(z_{t}-1\right) S_{t}^{s}-\left(x_{t}-1\right) \eta_{t} M_{t}^{s}=Q A_{t+1}
$$

I assume that $x_{t} \in(0, \bar{x})$ and $z_{t} \in[1, \bar{z})$, where the upper bound of both $z_{t}$ and $x_{t}$ implies that $A_{t+1}$ approaches zero and the household converts its whole period $t$ gold holdings to paper currency or specie. A law restricts smelting of coins back to consumable form, and therefore the lowest bound of the specie growth rate equals one. As a result of the household's choices, the laws of motion become

$$
M_{t+1}=M_{t}+\frac{\left(x_{t}-1\right)}{Q} \eta_{t} M_{t}^{s}
$$

and

$$
S_{t+1}=\delta S_{t}+(1-\phi)\left(z_{t}-1\right) S_{t}^{s}
$$

where $\delta \in(0,1)$ is the fixed depreciation rate of specie between period $t$ and $t+1$ and $\phi$ is brassage, the exogenous percentage cost of minting.

In this model, as in many countries during the historical gold standard period, the central bank functions as a financial intermediary by discounting bonds issued by the government and private bills issued by the firm. The central bank, after having accepted period $t$ gold deposit $\left(A_{t+1}^{g}-A_{t}^{g}\right)$ from the household, loans out cash to the government and the firm at the fixed rate $R \geq 1$. As a result $\left(1-\eta_{t}\right)$ is the ratio of the total nominal 
loan $B_{t}$ to the stock of central bank paper money.

$$
M_{t}^{s}=\frac{B_{t}}{1-\eta_{t}}
$$

As neither the government nor the firm have access to the gold endowment, they face a cash constraint in that they have to take a one period loan, or 'discount' $B_{t+1}$, from the central bank in order to be able to buy a public good, or respectively, pay for workers. The government starts the period $t$ by paying the principal and interest of its previous period's loan $\left(1-\theta_{t}\right) R B_{t}$ to the central bank. The public sector's share of the total discount $B_{t}$ is denoted by $\left(1-\theta_{t}\right)$. After the household has traded gold with the central bank, the government takes a new loan $\left(1-\theta_{t+1}\right) B_{t+1}$ to pay its current period $t$ expenditure, and at the end of the period $t$ the government imposes a tax $\hat{T}_{t}$ to the household. The government's period-by-period budget constraint is

$$
P_{t} G_{t} \leq\left(1-\theta_{t+1}\right) B_{t+1}-R\left(1-\theta_{t}\right) B_{t}+\hat{T}_{t}
$$

As in Schmitt-Grohe and Uribe (2000), the government is subject to a cash-in-advance constraint on its purchases of real goods $G_{t}$,

$$
P_{t} G_{t} \leq\left(1-\theta_{t+1}\right) B_{t+1}
$$

The representative firm uses labor $L_{t}$ it hires from the household to produce current output via its production technology $f\left(K, L_{t}\right)$. The firm produces, pays for its workers, sells the output to the household on demand for consumption on a cash basis, and after having received its revenue, the firm pays profits to the household and saves the principal and the interest of its current period discount that are paid to the central bank at the beginning of the following period. The cash-in-advance constraint for the firm's wage bill becomes

$$
W_{t} L_{t} \leq \theta_{t+1} B_{t+1},
$$


where $\theta_{t+1}$ is the firm's sector share of the total discount. The firm hires labor supplied by the household and the production takes place during the goods exchange. The firm takes its price $P_{t}$ from the market, wage from the contract and chooses $B_{t+1}$ and $L_{t}$ to maximize its profits. The household supplies whatever labor the firm demands. Given these specifications the firm's profit maximization problem becomes: maximize

$$
\sum_{t=0}^{\infty} \beta^{t} \Pi_{t}^{f}=\beta^{t}\left(P_{t} Y_{t}-R \theta_{t} B_{t}\right)
$$

subject to (9). The firm's production function is of form

$$
Y_{t}=f\left(K, L_{t}\right)=K^{1-\gamma} L_{t}^{\gamma}
$$

where $K$ is the fixed stock of capital, $L_{t}$ is labor demand in period $t, 0<\gamma<1$, and $f\left(K, L_{t}\right)$ is a strictly concave function. In equilibrium the real wage bill of the firm must be equal to the marginal product of labor

$$
\frac{\beta R W_{t}}{P_{t}}=f^{\prime}\left(L_{t}\right)
$$

I assume that the firm and the household agree on wages, which are set in advance for a period, before the period's gold endowment is realized, and before the central bank has made its decision over the period's discount. Although the nominal wage, as in Canzoneri and Dellas (1998), is chosen before the period's output or sales are known, it is set at a level that is expected to produce the real wage which equates labor supply and labor demand, and clears the goods market. To define the wage, the notional labor supply is set at one, although the actual labor supply and demand may differ from this. The contract wage for period $t$ is $W_{t}=\frac{\Omega_{t} f^{\prime}(1)}{\beta R}=\frac{\Omega \gamma K^{1-\gamma}}{\beta R}$, where $\Omega_{t}$ is the expected value of $P_{t}$ before the state of the world is known or the production started. If (11) and the contract wage is substituted back into (12) the labor demand of the representative firm can be written as $L_{t}=\left(P_{t} / \Omega_{t}\right)^{\frac{1}{1-\gamma}}$. If $K$ is normalized to 1 and the labor demand is substituted to (11), 
one obtains

$$
Y_{t}=L_{t}^{\gamma}=\left(\frac{P_{t}}{\Omega_{t}}\right)^{\frac{\gamma}{1-\gamma}} .
$$

Respectively, the real wage bill of the firm becomes $\frac{W_{t}}{P_{t}} L_{t}=\frac{\gamma}{\beta R}\left(\frac{P_{t}}{\Omega_{t}}\right)^{\frac{\gamma}{1-\gamma}}$ and the profits $\Pi_{t}^{f}=(1-\gamma) \Omega_{t}^{\frac{\gamma}{\gamma-1}} P_{t}^{\frac{1}{1-\gamma}}$. Any unanticipated changes in the price level will cause a difference between the expected and actual price level. If the price level increases unexpectedly, the real wage bill of the firm decreases and the employment increases to clear the labor market.

The central bank can either increase or decrease the economy's paper money supply through its discount policy. The rate of discretionary monetary expansion is denoted by $d_{t}$ and it is an inverse of the growth rate of the gold reserve ratio

$$
d_{t}=\frac{\eta_{t}}{\eta_{t+1}}
$$

The higher $d_{t}$, the lower the proportion of the circulating paper money stock that is backed by monetary gold. I assume $d_{t}$ to be bounded above by printing and storage constraint $\bar{d}$, which is assumed to be higher than $\bar{x}$ or $\bar{z}$. As stressed by Barro (1979), the real economy restricts gold supply, and therefore, $\bar{x}$ and $\bar{z}$, but the upper bound of discretionary paper money growth rate $\bar{d}$ can be taken to be arbitrarily large, i.e. $d_{t} \in(0, \bar{d})$ for all $t=0,1, \ldots$, and $\bar{x}, \bar{z}<\bar{d}<\infty$. The net growth rate of the economy's paper money supply $M_{t+1}^{s}$ on period $t+1$ can be defined as

$$
M_{t+1}^{s}=d_{t} x_{t} M_{t}^{s}
$$

This is just an alternative way to define (1): by substituting $d_{t}=\eta_{t} / \eta_{t+1}$ and $x_{t}=$ $A_{t+1}^{g} / A_{t}^{g},(15)$ becomes $(1)$.

Before solving for the household problem, let us scale the nominal variables in gold endowment constraint (3), the government and firm cash-in-advance constraints (8) and (9) and in the firm's problem with the economy's total paper money supply (15) so that 
$m_{t}=M_{t} / M_{t}^{s}, m_{t}^{s}=M_{t}^{s} / M_{t}^{s}=1, w_{t}=W_{t} / M_{t}^{s}, q=Q / M_{t}^{s}, p_{t}=P_{t} / M_{t}^{s}$ and $b_{t}=B_{t} / M_{t}^{s}$.

In the firm's problem the scaled expected price level $\Omega_{t}$ is denoted by $\omega_{t}$.

The household's preferences are given by the value of discounted utility per period,

$$
\sum_{t=0}^{\infty} \beta^{t} U\left(C_{t}, A_{t+1}\right)=\sum_{t=0}^{\infty} \beta^{t}\left[u\left(C_{t}\right)+\rho v\left(A_{t+1}\right)\right]
$$

where $0<\beta<1$, and functions $u$ and $v$ are concave and twice differentiable. In (16) $C_{t}$ denotes the consumption of a perishable good and $A_{t+1}$ the consumption of gold.

The household enters period $t$ with predetermined nominal money $m_{t}$ and depreciated specie worth $q \delta S_{t}$. The household then agrees on the nominal wage with the firm after which the household receives its gold endowment worth $q A^{s}$. Now the household is in the position to do its gold trade and minting: it chooses how much gold to consume, how much to mint and how much to convert to paper money. After these decisions the household's currency holdings are $m_{t}+q \delta S_{t}+q(1-\phi)\left(z_{t}-1\right) S_{t}^{s}+\left(x_{t}-1\right) \eta_{t} m_{t}^{s}$. Finally, the household receives its labor income $w_{t} L_{t}$. The rest of the currency holdings are transferred to the goods market. The cash-in-advance constraint that restricts household's consumption purchases becomes

$$
p_{t} C_{t} \leq m_{t}+q \delta S_{t}+q(1-\phi)\left(z_{t}-1\right) S_{t}^{s}+\left(x_{t}-1\right) \eta_{t} m^{s}+w_{t} L_{t}
$$

Since the central bank functions as a financial intermediary, labor income is available for consumption during the same period and enters into the cash-in-advance constraint. At the end of period $t$ the household receives the cash dividend payment $\pi_{t}^{f}$ from the firm, the interest yield $\pi_{t}^{c}$ from the central bank and carries the rest of the unspent currency, specie and gold into period $t+1$. Hence the household's budget constraint states

$$
d_{t} x_{t} m_{t+1}+q A_{t+1}+q S_{t+1} \leq m_{t}+q A_{t}+q \delta S_{t}+q A^{s}+w_{t} L_{t}+\pi_{t}^{f}+\pi_{t}^{c}-p_{t} C_{t}-q A_{t}-q \phi\left(z_{t}-1\right) S_{t}^{s}-\hat{t}_{t} .
$$


As in Carlstrom and Fuerst (1995) there are four markets present in this economy: the goods market, labor market, credit market and money market which in the gold standard setup is synonymous with the gold market. The private agents' problem must satisfy the resource constraint and market clearing conditions

$$
\begin{aligned}
C_{t}+G_{t} & =Y_{t} \\
p_{t} G_{t} & =\left(1-\theta_{t+1}\right) b_{t+1} \\
w_{t} L_{t} & =\theta_{t+1} b_{t+1} \\
S_{t}^{s} & =S_{t} \\
m_{t}^{s} & =m_{t} \\
b_{t+1} & =\left(1-\eta_{t+1}\right) m_{t+1}^{s}
\end{aligned}
$$

for all $t=0,1,2 \ldots$ By writing (14) for $\eta_{t+1}$, and substituting it and (15) to (24) gives $b_{t+1}=\left(1-\eta_{t} / d_{t}\right) x_{t} d_{t} m_{t}^{s}$. If this is substituted into (20) and (21) we get:

$$
\begin{aligned}
& p_{t} G_{t}=\left(1-\theta_{t+1}\right)\left(d_{t}-\eta_{t}\right) x_{t} m_{t}^{s} \\
& w_{t} L_{t}=\theta_{t+1}\left(d_{t}-\eta_{t}\right) x_{t} m_{t}^{s} .
\end{aligned}
$$

Like in Chari and Kehoe (1990), the private agents' behavior can be summarized by allocations $(\pi, \psi)$ and allocation rules $(\Pi, \Psi)$. For each period $t$ let $\psi_{t}=\left(\psi_{1, t}, \psi_{2, t}\right)$ be the household's allocations for the first and second stages of period $t$, where $\psi_{1, t}=\left(A_{t+1}, S_{t}^{s}\right)$ and $\psi_{2, t}=\left(C_{t}, S_{t+1}, m_{t}^{s}, m_{t+1}\right)$. Let $\psi=\left(\psi_{0}, \psi_{1}, \ldots\right)$ denote an infinite sequence of such allocations. The firm's allocation for period $t$ is $\pi_{t}=\left(L_{t}, b_{t+1}\right)$ and $\pi=\left(\pi_{0}, \pi_{1}, \ldots\right)$ denotes the infinite sequence of the firm's allocations. Formally a policy of the central bank is a sequence $d=\left\{d_{0}, d_{1}, \ldots\right\}$ of the discretionary money growth rates where $d_{t} \in(0, \bar{d})$. Allocation rules are the sequences of functions $\Psi=\left(\Psi_{0}, \Psi_{1}, \ldots\right)$ and $\Pi=\left(\Pi_{0}, \Pi_{1}, \ldots\right)$ that map policies into sequences of allocations: the household's allocation rule $\Psi(d)$ specifies the 
setting of $\psi_{t}=\left(A_{t+1}, S_{t}^{s}, S_{t+1}, C_{t}, m_{t}^{s}, m_{t+1}\right)$, and the firm's allocation rule $\Pi(d)$ specifies the setting of $\pi_{t}=\left(L_{t}, b_{t+1}\right)$, for each possible $d_{0}, d_{1}, \ldots$

The household's problem is to choose $A_{t+1}, S_{t+1}, S_{t}^{s}, C_{t}, m_{t+1}$ and $m_{t}^{s}$ to maximize (16) subject to (17), (18) and normalized (3), which becomes

$$
q \delta A_{t}+q A^{s}-q\left(z_{t}-1\right) S_{t}^{s}-\left(x_{t}-1\right) \eta_{t}=q A_{t+1}
$$

The first order conditions for intemporal consumption and gold consumption must satisfy

$$
\frac{q}{p_{t}} U_{C}(t)=U_{A}(t+1)+\beta \delta \frac{q}{p_{t+1}} U_{C}(t+1)
$$

Appendix A establishes that the cash-in-advance constraint (17) can be expressed as

$$
p_{t} C_{t}=1+q \delta+q(1-\phi)\left(z_{t}-1\right)+\left(x_{t}-1\right) \eta_{t}+\theta_{t+1}\left(d_{t}-\eta_{t}\right) x_{t}
$$

the condition for the price level becomes

$$
p_{t}=\omega_{t}^{\gamma}\left\{1+q \delta+q(1-\phi)\left(z_{t}-1\right)-\eta_{t}+d_{t} x_{t}\right\}^{1-\gamma}
$$

and consumption can be written as

$$
C_{t}=\omega_{t}^{-\gamma}\left\{1+q \delta+q(1-\phi)\left(z_{t}-1\right)-\eta_{t}+d_{t} x_{t}\right\}^{\gamma}-G_{t}
$$

From these initial solutions, especially from equations (13), (30), and (31), it can be seen that if the central bank's object is to maximize the household's utility, it is able to stimulate economic activity by creating surprise inflation in spite of the gold convertibility rule. If the central bank increases the discretionary money growth rate $d_{t}$ unexpectedly, the actual price level $p_{t}$ will be above the expected price level $\omega_{t}$, which will increase output, employment and consumption.

Within the above definitions and initial solutions of the government, firm and household's problems in hand, I turn to consider the equilibrium of the economy under the 
gold standard rule with the constant gold reserve ratio $\eta$, and then unanticipated deviation from this rule. The gold convertibility rule together with the constant $\eta$ has been analyzed by Barro (1979) and Goodfriend (1988), and also this paper considers it as an exogenous monetary policy rule that is not an outcome of an optimization problem. Policy under the gold standard, therefore, does not directly compare with an optimal policy under commitment, called the Ramsey policy, in Stokey (1989), Chari and Kehoe (1990), Ireland (1997) and Chang (1998).

\subsection{The Gold Standard with the Constant Reserve Ratio: Com- mitment Technology}

Consider the economy when at the beginning of time the central bank commits to the gold convertibility rule whilst keeping the gold reserve ratio constant at $\eta_{t}=\eta$ for all $t=0,1,2, \ldots$. This section shows that the gold standard with the constant reserve ratio is a commitment technology that solves the economy's time inconsistency problem that is created by the nominal wage stickiness.

Definition 1. The gold standard equilibrium with the constant reserve ratio $\eta$ is a policy $d=\left\{d_{t}=1 \mid t=0,1,2, \ldots\right\}$ and the agents' allocation rules $(\Pi, \Psi)$ that satisfy the firm's problem to choose $L_{t}$ and $b_{t+1}$ to maximize profits (10), and the household's problem to choose $A_{t+1}, C_{t}, m_{t}^{s}, S_{t}, S_{t}^{s}$ and $m_{t+1}$ to maximize its utility (16) subject to constraints (17), (18) and (27) for all $t=0,1,2, \ldots$, taking $A^{s}, p_{t}, R, \pi_{t}^{f}, \pi_{t}^{c}$ and $w_{t}$ given for all $t=0,1,2, \ldots$.

If $\eta_{t}=\eta$ for all $t=0,1,2, \ldots$ (14) indicates that $d_{t}=1$. The gold standard equilibrium is derived in Appendix A, which also establishes

Proposition 1. Under the gold standard rule with constant $\eta, z_{t}=1$, and in equilibrium $S_{t}^{s}=0$ for all $t=0,1,2, \ldots$, and $S_{t} \rightarrow 0$ when $t \rightarrow \infty$. 
Under the constant $\eta$ rule in equilibrium the utility maximizing household does not mint any new specie and only the gradually depreciating initial stock of specie remains in circulation. What is the intuition for this result? The cash-in-advance constraint imposes a cost on the economy in that some gold must be used for transaction purposes, either by converting it to paper money or minting it to coins. The household is better off in terms of welfare by using only paper currency as a medium of exchange, because specie depreciates and is involved with a minting cost that reduce the amount of gold in utility yielding form. In the real world there are physical restrictions on how small coins can be minted and used, but similar restrictions do not apply to paper currency, which can be printed in any denominations. The paper currency has two benefits over specie: firstly, through the government's expenditure constraint (8) and the firm's wage constraint (9) it facilitates financial intermediation; and secondly, by reducing the cost of acquiring money, it increases the household's welfare. Therefore, the model assumes that the specie stock gets arbitrarily small and insignificant in economic sense when time goes by, and the analysis is carried out under the assumption that $S_{t}=S_{t}^{s}=0$.

Proposition 1 together with the gold standard rule with constant $\eta$ implies that the total paper money supply (15) becomes $M_{t+1}^{s}=x_{t} M_{t}^{s}$. The gold endowment constraint (27) reduces into

$$
q \delta A_{t}+q A^{s}-\left(x_{t}-1\right) \eta_{t}=q A_{t+1}
$$

Period $t$ price level and consumption become

$$
p_{t}=\omega_{t}^{\gamma}\left\{1-\eta+x_{t}\right\}^{1-\gamma}
$$

and

$$
C_{t}=\omega_{t}^{-\gamma}\left\{1-\eta+x_{t}\right\}^{\gamma}-G_{t}
$$

Proposition 2. The perfect gold standard rule solves the economy's time inconsistency problem, and eliminates any uncertainty about the money growth rate. 
Proof: Under the gold standard rule with constant $\eta$ the central bank cannot stimulate the economy by monetary transfers as $d_{t}=1$, neither there is uncertainty about the future money growth rate $x_{t}$, because $A^{s}$ is fixed and the household chooses $x_{t}$ so that $\omega_{t}=p_{t}$ for all $t=0,1,2, \ldots$. To demonstrate why the household does not have an incentive to choose $x_{t}$ which would yield the actual money growth rate to be above the expected money growth rate, consider the following: assume that the household takes more gold to the central bank to be converted to notes than was expected during the wage bargain. Equations (33) and (34) imply that both the price level and consumption increase if the rate of monetary expansion proportionate to monetary gold, $x_{t}$, increases above the rate used in contract wage setting at the previous period. However, this does not hold in equilibrium. Using the language of Ireland (1997), if at period $t-1$ wage setters' expectation on the money growth rate at next period is $x^{e}$, but the actual money growth rate is $x_{t}=x^{e}+\Delta_{t}$, where $\Delta_{t} \in(0, \infty)$, from $(33)$ the price level increases, which decreases real wages, through (13) increases labor demand and through (34) increases consumption. Now the wage setters would respond by adjusting their wage expectations to $x^{e}+\Delta_{t}$, then the household would have an incentive to set $x_{t+1}$ to $x_{t+1}=x^{e}+\Delta_{t+1}$ where $\Delta_{t}<\Delta_{t+1}<\infty$. The process would continue until $x_{t}$ would approach its upper bound $\bar{x}=\left(\frac{\delta A+A^{s}}{\eta}+1\right)-$ all gold holdings converted to paper currency - and the price expectations $\omega_{t}$ would approach the upper bound of the price level $\bar{p}=\bar{\omega}=\left({\frac{\delta A+A^{s}}{\eta}}^{s} \eta\right)$. As in Barro and Gordon (1983a) any systematic benefits of inflation disappear in equilibrium. However, in this commodity standard set-up there is an additional constraint (32) which limits the household's willingness to convert gold to paper money. If the money growth rate approaches its upper bound, the household converts its whole gold endowment to paper currency. Simultaneously, $A_{t+1}$ - gold in utility yielding form - approaches zero, which reduces current period utility, while impact of gold conversion on $C_{t}$ disappears since 
expectations have been adjusted.

The policy $d=1$ under the gold standard together with particular allocation $\psi_{t}=$ $\Psi(1)$ and $\pi_{t}=\Pi(1)$ is called the gold standard outcome and is denoted by $\left(1, \pi^{g}, \psi^{g}\right)$. It describes the sequences of equilibrium prices and quantities that are obtained when the central bank manages gold reserves and converts gold to paper currency on demand according to the exogenous gold standard rule, and the private agents respond to the exogenous flow of gold by maximizing utility and profits. The gold standard outcome can be described by the following two proposition:

Proposition 3. The gold standard outcome implies that in equilibrium $d_{t+i}=$ $1, \omega_{t+i}=p_{t+i}, \quad L_{t+i}=1, C_{t+i}=Y_{t+i}-G_{t+i}=1-G_{t+i}$ and $A_{t+i+1}=\delta^{i} A_{0}+$ $\sum_{t}^{i} \delta^{i-1}\left[A^{s}-q^{-1}\left(x_{t+i}^{g}-1\right) \eta\right]$ for all $i=0,1,2, \ldots$

Proof: In equilibrium $\omega_{t+i}=p_{t+i}$ and by substituting it and (19) into (13) we get that $C_{t+i}=1-G_{t+i}$ for all $i=0,1,2, \ldots$ By setting $m_{t+i}^{s}=1$ in (32) and generalizing (32) gives $A_{t+i+1}=\delta^{i} A_{0}+\sum_{i=0} \delta^{i-1}\left[A^{s}-q^{-1}\left(x_{t+i}^{g}-1\right) \eta\right]$.

Under the gold standard with constant $\eta$ the first-order-condition for $m_{t+i+1}$ is $x_{t+i} \lambda_{t+i}=$ $\beta\left(\lambda_{t+i+1}+\mu_{t+i+1}\right)$, where $\lambda$ and $\mu$ are the Lagrangian multipliers of the household's budget and cash-in-advance constraints (see Appendix A). Let us now assume that $x_{t+i}$ is bound below by $\beta$ for all $i=0,1,2, \ldots$ so that in the steady state $\mu$, the shadow value of money, is non-negative and the gold standard equilibrium in which paper money is always used as a medium of exchange, exists.

Proposition 4. Suppose that $x_{t+i}^{g} \in\left(\beta, \frac{\delta A+A}{\eta}^{s}+1\right)$. Welfare under the perfect gold standard equilibrium is maximized when $x_{t+i}^{g}$ equals $\beta$ for all $i=0,1,2, \ldots$.

Proof: In equilibrium $C_{t+i}=1-G_{t+i}$. The lower $x_{t+i}^{g}$ the higher is $A_{t+i+1}$ for given $A_{0}$. Welfare increases when $x_{t+i}^{g}$ approaches its lower bound $\beta$. The discounted utility $\sum_{i=0}^{\infty} \beta^{t} U\left[1-G_{t+i}, A\left(x_{t+i}^{g}\right)\right]$, where $A_{t+i+1}=\delta^{i} A_{0}+\sum_{t}^{i} \delta^{i-1}\left[A^{s}-q^{-1}\left(x_{\tau+i}^{g}-1\right) \eta\right]$ is 
strictly decreasing on $\left(\underline{x}^{g}, \bar{x}^{g}\right)=\left(\beta, \frac{\delta A+A}{\eta}^{s}+1\right)$ for all $i=0,1,2, \ldots$ When $\underline{x}^{g}=\beta$ for all $i=0,1, \ldots$ the discounted utility equals

$\sum_{i=0}^{\infty} \beta^{i} U^{g}\left(1-G_{t+i}, A(\beta)\right)=\sum_{i=0}^{\infty} \beta^{i}\left\{u^{g}\left(1-G_{t+i}\right)+\rho v^{g}\left(\frac{1}{1-\delta}\left[q A^{s}-q^{-1}(\beta-1) \eta\right]\right)\right\}$

If $G_{t+i}$ is constant (35) simplifies to $\frac{1}{1-\beta}\left\{u^{g}(1-G)+\rho v^{g}\left(\frac{1}{1-\delta}\left[q A^{s}-q^{-1}(\beta-1) \eta\right]\right)\right\}$. Under the gold standard with constant $\eta$ the household consumes its whole gold endowment and converts some of its existing paper currency to gold in equilibrium. When the central bank commits to the gold convertibility rule and to keep $\eta$ constant, the bank loses the ability to boost production and employment by increasing the discretionary money growth rate through discounting, hence the gold standard rule solves the time inconsistency problem which arises from the sticky wage structure.

\subsection{The Suspension of the Gold Standard Rule: Accommoda- tion}

Let us assume that the economy has been running for a sufficiently long period of time, so that it has reached its long-run gold standard equilibrium described by propositions 3 and 4. In what follows I assume that the economy experiences an entirely unanticipated switch from the normal state, which I call 'peace' to the bad state, 'war'. All agents recognize that war can last for several periods, but not forever. The exogenous change between the states occurs after the firm and the household have set wages, but it is observed simultaneously by both private and public agents. The war state differs from peace in that the gold endowment is zero and the household's gold demand is exogenously defined to approach $A^{g}$, the central bank's gold stock. As a result of a bank run, the lowest bound of $x$ is no longer well defined by $\beta$. If the central bank did not suspend the gold standard, by (33) the price level would fall and the expected price level $\omega$ would be above the actual 
price level, and, as stated in section 2.1, this would have adverse effects on employment and production. From the firm and government cash-in-advance constraints, any gold conversion would reduce the reserves on which the firm or the government can borrow. Finally, from (34), a fall in the price level would reduce private consumption.

To restore monetary stability at the beginning of war, the central bank deviates from the gold standard rule and starts following a new monetary policy rule called the suspension rule. The deviation is excusable and the new rule implies that during war the central bank does not convert paper notes to gold immediately, but promises to resume the gold convertibility at the old gold reserve ratio $\eta$ and par value $q$ at some future point after the crises has passed and the gold reserve is again at its pre-war level.

Definition 2 The policy of the central bank during the suspension is a plan $\sigma$ according to which the central bank (i) issues only unbacked paper money during war, (ii) immediately after the war starts adjusting economy to the gold standard by withdrawing paper money from circulation whilst still preventing money-to-gold conversion, and (iii) resumes the gold standard at old par value $q$ when $\eta$ is at its pre-war level.

Figure (1) illustrates how the plan divides the suspension period into two stages, the monetary expansion periods during war and the adjustment periods after the arrival of peace. During war the suspension enables the central bank to stabilize production and consumption by its private discount policy, and given that $G$ increases during the war, yield the government some seigniorage by its public discount policy. After the arrival of peace the central bank adjusts the economy by constraining its discounts. The benefit of this policy is the timing of potential reduction in welfare after the war, not during the war. In what follows I assume that periods between $\tau$ and $\tau+j-1$ are the wartime monetary expansion periods. Peace arrives in period $\tau+j$ and periods between $\tau+j$ and 
$\tau+S, S<\infty$, are the adjustment periods. Period $\tau+S$ is the final suspension period.

[Insert Figure 1 here.]

The policy plan $\sigma$ induces future histories, and the policy plan together with agents' allocation rules induce future utilities. For each $i=0,1,2, \ldots, S$, denote the history of the central bank's policy through time $\tau+i$ by $h_{\tau+i}=\left\{d_{\tau+k} \mid k=0,1, \ldots i-1\right\}$, and $h_{-1}=\left\{d_{t}=1 \mid t=0,1, \ldots, \tau-1\right\}$. For any policy plan $\sigma=\left\{\sigma_{0}, \sigma_{1}, \ldots\right\}$ let $\sigma^{\tau+i}=$ $\left\{\sigma_{\tau+i} \mid i=0, \ldots, S\right\}$ denote a sequence of policy plans from time $\tau$ onward and $\sigma^{\tau+i}$ the continuation of $\sigma$. Policy plan $\sigma$ specifies the discretionary money growth rate $d_{\tau+i}$ during the suspension conditional on the realization of history $h_{\tau+i}$.

The sequence of events between periods $\tau$ and $\tau+S$ is the following. At the beginning of the first stage of period $\tau+i$, the household and the firm agree on nominal wages, then $A^{s}$ is observed by all, and then, the central bank announces its policy plan $\sigma$. Next, faced with the history $h_{\tau+i-1}$, the household chooses the first-stage allocation of $\psi_{1, \tau+i}\left(h_{\tau+i-1}\right)=$ $\left(A_{\tau+i+1},\right)$ and a contingency plan for setting future actions for all possible future histories. By definition, if $A^{s}=0, \psi_{1, \tau+i}\left(h_{\tau+i-1}\right)=\delta^{i}\left(A_{\tau}\right)$, i.e. the household's gold holdings consists entirely of depreciating gold holdings it had at the beginning of war. The central bank, faced with the history $h_{\tau+i-1}$, sets time $\tau+i$ discretionary money growth rate $\sigma_{\tau+i}\left(h_{\tau+i-1}\right)=d_{\tau+i}$ and chooses a contingency plan for setting future money growth rates. At the second stage of period $\tau+i$, both the household and the firm face the history $h_{\tau+i}=\left[h_{\tau+i-1}, \sigma\left(h_{\tau+i-1}\right)\right]=\left(h_{\tau+i-1}, d_{t+i}\right)$. The household chooses its second stage allocation $\psi_{2, \tau+i}\left(h_{\tau+i}\right)=\left(C_{\tau+i}, b_{\tau+i}, m_{\tau+i}^{s}, m_{\tau+i}\right)$ and the contingency plan for all future histories, and the firm chooses its allocation $\pi_{t+i}\left(h_{\tau+i}\right)=\left(L_{\tau+i}, B_{\tau+i+1}\right)$ conditional on realization of history $h_{\tau+i}$. These definitions recognize that the household makes its decision in two stages and firm in one.

As in Ireland (1997) without commitment technology $p_{\tau+i}$ and $w_{\tau+i}$ are also functions 
of the history of the central bank's policy. Starting from any date after the announcement to suspend the cash payments, the private agents can forecast these variables using the recursive formula $h_{\tau+i}=\left[h_{\tau+i-1}, \sigma_{\tau+i}\left(h_{\tau+i-1}\right)\right]$ where $i=0,1, \ldots, S$; and their knowledge of price level, wage and interest rate determination processes.

Consider first the private agents' problem during the suspension of the gold standard rule. The representative firm's problem is to choose $L_{\tau+i}\left(h_{\tau+i}\right)$ and $b_{\tau+i+1}\left(h_{\tau+i}\right)$ to maximize

$$
\sum_{i=0}^{\infty} \beta^{\tau+i} \Pi_{\tau+i}^{f}=\beta^{\tau+i}\left[p_{\tau+i}\left(h_{\tau+i}\right) Y_{\tau+i}-R \theta_{\tau+i} b_{\tau+i}\left(h_{\tau+i-1}\right)\right]
$$

subject to $w_{\tau+i}\left(h_{\tau+i}\right) L_{\tau+i}\left(h_{\tau+i}\right) \leq \theta_{\tau+i+1} b_{\tau+i+1}\left(h_{\tau+i}\right)$ taking $w_{\tau+i}\left(h_{\tau+i}\right), p_{\tau+i}\left(h_{\tau+i}\right)$ and $h_{\tau+i}=\left[h_{\tau+i-1}, \sigma\left(h_{\tau+i-1}\right)\right]$ given for all $i=0,1, \ldots, S$.

The household chooses $C_{\tau+i}, A_{\tau+i+1}, m_{\tau+i}^{s}$, and $m_{\tau+i}$ to maximize

$$
\sum_{i=0}^{j-1} \beta^{i} U\left[C_{\tau+i}\left(h_{\tau+i}\right), \delta^{i} A_{\tau}\right]+\sum_{i=j}^{\infty} \beta^{i} U\left[C_{\tau+i}\left(h_{\tau+i}\right), A_{\tau+i+1}\left(h_{\tau+i-1}\right)\right]
$$

subject to the the cash-in-advance constraint

$$
p_{\tau+i} C_{\tau+i} \leq m_{\tau+i}+\left(x_{\tau+i}-1\right) \eta_{\tau+i} m_{\tau+i}^{s}+\theta_{\tau+i} w_{\tau+i} L_{\tau+i}
$$

the budget constraint

$$
d_{\tau+i} x_{\tau+i} m_{\tau+i+1}+q A_{\tau+i+1} \leq m_{\tau+i}+q \delta A_{\tau+i}+\theta_{\tau+i} w_{\tau+i} L_{\tau+i}+\pi_{\tau+i}^{f}+\pi_{\tau+i}^{c}-p_{\tau+i} C_{\tau+i}-\hat{t}_{t}
$$

and the endowment constraint, which during the war periods $i=0, \ldots, j-1$,reduces to

$$
\delta A_{\tau+i}=A_{\tau+i+1}
$$

and during the adjustment periods $i=j, \ldots, S$ to

$$
q \delta A_{\tau+i}+q A_{\tau+i}^{s}-\left(x_{\tau+i}-1\right) \eta_{\tau+i} m_{\tau+i}^{s}=q A_{t+i+1} .
$$

From these definitions it follows that $x_{t}=1$ when $i=0, \ldots, j-1$ (expansion), $x \geq 1$ when $i=j, \ldots, S$ (adjustment) and $x$ defined as under the gold standard if the gold standard is resumed when $i=S+1$. 
At each period $\tau+i$ when $i=0,1, \ldots, S$, the central bank takes $h_{\tau+j-1}$ as given and chooses a continuation policy $\sigma^{\tau+i}$ to solve the following problem: choose $d_{\tau+i}$ to maximize (37), where $C_{\tau+i}$ and $A_{\tau+i+1}$ are determined by $\Psi$ and $\Pi$, subject to the terminal condition

$$
m_{\tau+S+1}=\frac{q A_{\tau+S+1}^{g}}{\eta}
$$

Appendix B establishes that the terminal condition (42) can be written as

$$
\left(\prod_{i=0}^{S} x_{\tau+i} d_{\tau+i}-1\right) \eta m_{\tau}=Q \sum_{i=j}^{S}\left(\delta A_{\tau+i}+A^{s}-A_{\tau+i+1}\right) \text { for } S<\infty
$$

The terminal condition states that monetary gold must be proportional to the circulating money stock, and $\eta_{\tau+i}=\eta$, by the time of the resumption. Incorporated in plan $\sigma_{i}$, the terminal condition implies that once the gold flow resumes, the central bank must set $d_{\tau+i}<1, i=j, \ldots, S$ in order to withdraw the fiat money from circulation. The net discretionary money growth satisfies $\prod_{i=0}^{S} d_{\tau+i}=1$. The price level and consumption during the wartime expansion periods become:

$$
\begin{aligned}
& p_{\tau+i}\left(h_{\tau+i-1}\right)=\omega_{\tau+i}^{\gamma}\left(1+d_{t+i}\left(h_{\tau+i-1}\right)-\eta_{t+i}\right)^{1-\gamma} \\
& C_{\tau+i}\left(h_{\tau+i-1}\right)=\omega_{\tau+i}^{-\gamma}\left(1+d_{t+i}\left(h_{\tau+i-1}\right)-\eta_{t+i}\right)^{\gamma}-G_{\tau+i}
\end{aligned}
$$

and during the adjustment periods respectively:

$$
\begin{aligned}
p_{\tau+i}\left(h_{\tau+i-1}\right) & =\omega_{\tau+i}^{\gamma}\left[1+d_{t+i}\left(h_{\tau+i-1}\right) x_{t+i}\left(h_{\tau+i-1}\right)-\eta_{t+i}\right]^{1-\gamma} \\
C_{\tau+i}\left(h_{\tau+i-1}\right) & =\omega_{\tau+i}^{-\gamma}\left[1+d_{t+i}\left(h_{\tau+i-1}\right) x_{t+i}\left(h_{\tau+i-1}\right)-\eta_{t+i}\right]^{\gamma}-G_{\tau+i} .
\end{aligned}
$$

As the discretionary money 'withdrawal' rate during the adjustment satisfies $0 \leq d_{\tau+i} \leq 1$, the price level is lower during the adjustment than expansion. Whether the consumption is lower during adjustment than war depends also on $G_{\tau+i}$.

Definition 3. A sustainable equilibrium $(\sigma, \Pi, \Psi)$ consists of a policy plan $\sigma$ and a set of allocation rules $(\Pi, \Psi)$ that satisfy: (i) given a policy plan $\sigma$ and the household's 
allocation rule $\Psi$, the continuation of $\Pi$ solves the firm's problem to maximize (36) subject to $L_{\tau+i}$ and $b_{\tau+i}$, and history $h_{\tau+i}$; (ii) given $\sigma$ and the firm's allocation rule $\Pi$, the continuation of $\Psi$ solves the household's problem to maximize (37) subject to (38), (39), (41) and history $h_{\tau+i-1}$ and $h_{t+i}$; (iii) given the allocation rules $(\Psi, \Pi)$, the continuation of plan $\sigma$ solves the central bank's problem to choose $d_{\tau+i}$ to maximize (37) for every history $h_{\tau+i-1}$ and the terminal condition (43).

The sustainable outcome $(d, \psi, \pi)$ describes the sequence of equilibrium quantities and prices that are obtained when the central bank chooses $d_{\tau+i}$ sequentially to maximize (37) subject to (43), and private agents respond optimally. As in Chari and Kehoe (1990) and Ireland (1997) the set of sustainable outcomes is formed recursively: starting from $h_{-1}=1$, construct $h=\left(h_{\tau}, h_{\tau+1}, \ldots\right)$ and $d=\left(d_{\tau}, d_{\tau+1}, \ldots\right)$ recursively using $d_{\tau+i}=$ $\sigma_{\tau+i}\left(h_{\tau+i-1}\right)$ and $h_{\tau+i}=\left[h_{\tau+i-1}, \sigma_{\tau+i}\left(h_{\tau+i-1}\right)\right]$. Then for all $i=0,1, \ldots, S$ construct $\pi=\left(L_{\tau}, L_{\tau+1}, \ldots ; b_{\tau}, b_{\tau+i, \ldots}\right)$ using $L_{\tau+i}, b_{\tau+i}=\Pi\left(h_{\tau+i}\right)$ and $\psi=\left(\psi_{\tau}, \psi_{\tau+1}, \ldots\right)$ using

$\psi_{1, \tau+i}=\Psi\left(h_{\tau+i-1}\right)$ and $\psi_{2, \tau+i}=\Psi\left(h_{\tau+i}\right)$ for all $i=0,1, \ldots$ These recursive definitions are used in the next section to illustrate how the central bank's plan $\sigma$, if it is sustainable, leads to the resumption of the gold standard.

\section{Sustainability of the Resumption Plan}

\subsection{Sustainable Outcomes}

In this section I use the model of sustainable plans to address the question raised in the Introduction: What made monetary policy credible during suspension periods in the absence of the commitment technology?

Consider the household's decision making problem both during the expansion and the adjustment periods. During war when $A^{s}=0$ the household can either mint some of 
its existing gold holdings to specie, or use inconvertible paper currency as a medium of exchange. Minting specie is not welfare maximizing because minting reduces gold in utility yielding form, and once coined, specie is not convertible back to gold, and therefore, the household uses paper currency as a medium of exchange. The cash-in-advance constraint formalizes this assumption and embodies some relevant historical evidence. According to Feavearyear (1963) p 184 during the Suspension Period of 1797-1821 in England the public 'accepted the notes because there was nothing else and because they served the purposes of trade for the time being as well as gold'.

The war, however, lasts for a finite time and the return of the gold endowment gives the household an opportunity to start minting coins and stop using paper money if it considers the central bank's plan to resume the gold standard not to be credible. The central bank has an incentive to avoid the adjustment process, because withdrawing fiat money from circulation has adverse real effects on the economy with sticky nominal wages. It is the threat imposed by the household's revenge strategy that may support the resumption of the gold standard. As in Chari and Kehoe (1990) and Ireland (1997), the set of sustainable outcomes, which in this model refers to the outcomes that result of the resumption of the gold standard, can be characterized by adapting Abreu (1988) optimal penal codes to monetary policy games played between a benevolent central bank and a large number of private agents.

The autarky plan $\sigma^{a}$ is defined as follows. Private agents agree on $w_{\tau+i}$, then all sectors observe that $A^{s}>0$. The household then chooses a first-stage allocation of $\psi_{1, \tau+i}\left(h_{\tau+i-1}\right)>0$ where $i \geq j$ and a contingency plan for setting future actions for all possible future histories. The central bank, given the history $h_{\tau+i-1}$, sets the time $\tau+i$ discretionary money growth rate in following manner: for any $h_{\tau+i-1}$ let $\sigma^{a}\left(h_{\tau+i-1}\right)$ be 
the optimal money growth rate in the problem: maximize

$$
U^{a}\left(x_{\tau+i}, d_{\tau+i}\right)=\max _{d_{\tau+i}} U\left\{C_{\tau+i}\left(h_{\tau+i}\right), A_{\tau+i+1}\left[x_{\tau+i}\left(h_{\tau+i-1}\right)\right]\right\}
$$

subject to $d_{\tau+i} \leq \bar{d}$, where $A_{\tau+i+1}$ is given by $\psi_{1, \tau+i}\left(h_{\tau+i-1}\right)$ and $i \geq j$. Next, at the second stage of period $\tau+i$, both the household and the firm face the history $h_{\tau+i}=$ $\left[h_{\tau+i-1}, \sigma^{a}\left(h_{\tau+i-1}\right)\right]$. The household chooses its second stage allocation $\psi_{2, \tau+i}\left(h_{\tau+i}\right)$ and the contingency plan for all future histories and the firm chooses its allocation $\pi_{t+i}\left(h_{\tau+i}\right)$.

Proposition 5. The policy under the autarky plan is $\sigma_{\tau+i}^{a}\left(h_{\tau+i-1}\right)=d^{a}=\bar{d}$.

Proof: Period $\tau+i$ consumption (47) is strictly increasing in $d_{\tau+i} \in(0, \bar{d})$ and $d_{\tau+j}=\bar{d}$ maximizes (48). Instead of setting $d_{\tau+i} \in(0,1)$ to withdraw paper money from circulation at the beginning of the adjustment period, the central bank surprises the private agents by unanticipated money creation.

Propositions 6. The welfare under the autarky, $U^{a}$, is the maximum current-period utility at period $\tau+i$ which the central bank can obtain by deviating from its policy plan $\sigma_{\tau+i}\left(h_{\tau+i-1}\right)$ at time $\tau+i$, given that the central bank has followed the plan in every period prior to the deviation.

Proof: The policy under the autarky does not have an effect on the first stage allocation under autarky, $\psi_{1, \tau+i}^{a}=\Psi^{a}\left(h_{\tau+i-1}\right)=A_{\tau+i+1}$ but the second stage allocation $\psi_{2, \tau+i}^{a}=\Psi^{a}\left(h_{\tau+i}\right)$ implies that consumption becomes

$$
\bar{C}_{\tau+i}^{a}=\omega_{\tau+i}^{-\gamma}\left[1-\eta_{t+i}+\bar{d} x_{t+i}\right]^{\gamma}-G_{\tau+i}
$$

where $x_{\tau+i}\left(h_{\tau+i-1}\right) \geq 1 . \quad \bar{C}_{\tau+i}^{a}$ is the maximum current-period consumption at period $\tau+i$ the central bank can achieve by supplying the maximum amount of paper money.

As the result of the deviation from the declared policy plan $\sigma$ the economy reverts to the commodity money system which is a static equilibrium, because the allocation rules 
and policy plans do not depend on the past history. The household has abandoned the paper currency altogether, only specie circulates and financial intermediation does not exist.

Definition 3: The static equilibrium $\left(\sigma^{s}, \Psi^{s}, \Pi^{s}\right)$ is defined as follows. For any history $i>j,\left[h_{\tau+i-1}, \sigma_{\tau+i}^{s}\left(h_{\tau+i-1}\right)\right]=\emptyset$. For every history $h_{\tau+i-1}$ the rule specifies that the household does not take any gold to the central bank, but mints some of its gold holdings to specie. With the given history $h_{t+i}$ the household chooses $A_{\tau+i+1}, S_{\tau+i}, S_{\tau+i}^{s}$, and $C_{\tau+i}$ to maximize

$$
U^{s}=\max _{z_{\tau+i}} \sum_{i=0}^{\infty} \beta^{t} U\left[C_{\tau+i}, A_{\tau+i+1}\left(z_{\tau+i}\right)\right]
$$

subject to the specie-in-advance constraint

$$
p_{\tau+i} C_{\tau+i} \leq q \delta S_{\tau+i}+q(1-\phi)\left(z_{\tau+i}-1\right) S_{\tau+i}^{s}
$$

the budget constraint

$$
\begin{aligned}
z_{\tau+i} S_{\tau+i+1}+q A_{\tau+i+1} \leq & q \delta S_{\tau+i}+q \delta A_{\tau+i}+w_{\tau+i} L_{\tau+i}+\pi_{\tau+i}^{f} \\
& +q A_{\tau+i}^{s}-p_{\tau+i} C_{\tau+i}-q \phi\left(z_{\tau+i}-1\right) S_{\tau+i}^{s}-\hat{t}_{\tau+i}
\end{aligned}
$$

and the gold endowment constraint

$$
q A^{s}+q \delta A_{\tau+i}-q A_{\tau+i+1}=q\left(z_{\tau+i}-1\right) S_{\tau+i}^{s}
$$

for all $i>j$. The nominal variables have been scaled with $S_{\tau+i+1}^{s}=z_{\tau+i} S_{\tau+i}^{s}$.

As the paper currency has lost its value, specie is the only medium of exchange. Without paper money the central bank is not able to offer financial intermediation services.

Proposition 7. The static outcome $\left(\emptyset, \psi^{s}, \pi^{s}\right)$ implies that $C_{\tau+i}=1-G_{\tau+i}, L_{\tau+i}=1$ and $A_{\tau+i+1}=\delta A_{\tau+i}+A^{s}-q^{-1}(\underline{z}-1)$ where $\underline{z} \geq 1$.

Proof: The proof is identical to the proof of Proposition 3, but $m^{s}$ and $m$ are replaced with $S^{s}$ and $S$. 
Proposition 8. Welfare under the static equilibrium,

$$
U^{s}\left(1-G_{\tau+i}, A\left(z^{s}\right)\right)=\left[u^{s}\left(1-G_{t+i}\right)+v^{s}\left(\delta A_{\tau+i}+A^{s}-q^{-1}(\underline{z}-1)\right)\right]
$$

is lower than under the gold standard.

Proof: The optimal money growth rate under the gold standard, $x^{g}=\beta<1$, but the optimal specie supply rate $z \geq 1$ because the smelting of specie is illegal. In the steady state the laws of motion (5) implies that $z=1+(1-\delta) /(1+\phi)$. The faster the depreciation of specie or the higher the brassage, the higher is $z$. Under the static equilibrium gold specie is used as a medium of exchange, which together with $\delta$ and $\phi$ reduce $A_{\tau+i+1}$, gold in the utility yielding form.

The next proposition characterizes the entire set of sustainable outcomes which ensure the resumption of the gold standard. For an arbitrary sequence of policies and allocations $(d, \pi, \psi)$, the revert-to-static policy plans specify continuation with the plan to resume the gold standard as long as the policy defined by the original plan has been chosen in the past. The allocation rule specifies that immediately after a deviation the household and the firm will follow the rule defined by the static allocation rule and stay in this static state in all subsequent periods.

Proposition 9. Sustainability of the resumption of the gold standard: let $d$ be an arbitrary policy and $(\pi, \psi)$ an arbitrary allocation. Then the return to the perfect gold standard is sustainable if and only if $(d, \pi, \psi)$ satisfies

$$
\sum_{i=j}^{S} \beta^{j-i} U_{\tau+i}+\sum_{i=S+1}^{\infty} \beta^{S+j-i} U_{\tau+i}^{g} \geq U^{a}+\frac{\beta}{1-\beta} U^{s},
$$

where $A_{\tau+i+1}, C_{\tau+i}, S_{\tau+i+1}, S_{\tau+i}^{s}, m_{\tau+i+1}$ and $m_{\tau+i}^{s}$ are given by $\psi$, and $L_{\tau+i}$ and $b_{\tau+i}$ are given by $\pi$.

Proposition 9 implies that the resumption of the gold standard is sustainable, if the adjustment to the gold standard between periods $\tau+j$ and $\tau+S$ and gold standard 
thereafter will yield at least as much utility as default on period $\tau+j$ and static state thereafter. Incentive compatibility constraint (55) completely characterizes the conditions under which an arbitrary sequence of policies and allocations is sustainable. The adjustment between periods $\tau+j$ and $\tau+S$ and the gold standard thereafter must provide at least as much utility from $\tau+j$ forward than what is obtained by deviating from the resumption plan in period $\tau+j$ and reverting to the autarky thereafter. Inequality (55) is the key result of this paper. It suggests that countries returned to the gold standard after war time suspensions because the benefits of the gold standard did outweigh the cost of adjustment, which was a necessary procedure for resumption.

\subsection{The Suspensions and Sustainable Plans: Some Examples}

The ultimate objective of this example is to illustrate the logic behind Proposition 9, and to define under what conditions resumption of the gold standard is a sustainable plan. To avoid having to work with approximations I develop a simple example in which war lasts for a period and the central bank's plan $\sigma$, which defines monetary policy during the suspension, implies that the bank withdraws all wartime fiduciary paper money from circulation during the period that follows immediately after the war period.

During the suspension the central bank's problem is to choose the optimal discretionary money growth rate $d_{w a r}$ to maximize the household's discounted net utility (37) subject to requirements that prices and quantities are determined by allocation rules $(\Pi, \Psi)$ that solve the firm and household problems and are consistent with the terminal condition (42) and plan $\sigma$. In this example I assume that $G_{w a r}=1$ and $G_{p e a}=0$. The utility function (37) takes a $\log$-linear form $\left[\log C_{\tau+i}+\rho \log A_{\tau+i+1}\right]$ and parametric values are following: $\beta=0.99, K=10, \gamma=0.5, q=1, \rho=0.5$ and $A^{s}=2$. I choose the parameter values so that under the gold standard steady state the ratio between the 
utility yielded from gold to the utility from consumption is relatively small, i.e. 0.15. Price expectations are formed so that $\omega_{\tau+i}=p_{\tau+i-1}$, thus $\omega_{w a r}=p_{\text {gold }}$, and the price level during war exceeds the expected price level.

If the adjustment period follows the war period, the terminal condition (42) implies that all fiduciary paper money issued during war must be withdrawn from circulation on the following adjustment period. As a result the withdrawal rate $d_{a d j}$ becomes an inverse of $d_{w a r}$, i.e. $d_{a d j}=1 / d_{w a r}$, so that (42) holds. Furthermore, the gold backing ratio during adjustment can now be defined in terms of $d_{\text {war }}$ : From (14) we have that $\eta_{a d j}=\eta / d_{w a r}$, in which $\eta$ is the constant gold reserve ratio during the gold standard. Given above specifications, the household's consumption during the war and adjustment periods become:

$$
\begin{aligned}
C_{w a r} & =\omega_{w a r}^{-\gamma}\left(1+d_{w a r}-\eta\right)^{1-\gamma}-G_{w a r} \\
C_{a d j} & =\omega_{a d j}^{-\gamma}\left(1+d_{a d j}-\eta_{a d j}\right)^{1-\gamma}-G_{p e a}=\omega_{a d j}^{-\gamma}\left(1+\frac{1-\eta}{d_{w a r}}\right)^{1-\gamma}-G_{p e a} .
\end{aligned}
$$

Equations (56) and (57) imply that $d_{w a r}$ increases $C_{w a r}$ and wartime welfare $U\left(C_{w a r}\right)$, but respectively, reduces $C_{a d j}$ and welfare during the adjustment period.

Figure 2 plots both sides of the inequality (55) for $d_{w a r}$. The circled line is the left hand side of (55), the discounted net utility under the adjustment and the gold standard. As can be seen from figure 2 , the discounted utility falls when $d_{\text {war }}$ increases, because the household's welfare function during the adjustment period is a decreasing function of $d_{\text {war }}$.

The solid line in figure 2 plots the right hand side of inequality (55). By contrast, the relative benefit of a default increases if $d_{\text {war }}$ increases because the higher $d_{\text {war }}$, the higher the welfare loss of adjustment is going to be. By defaulting the plan to resume the gold standard the central bank avoids the costly adjustment process. I assume, loosely based on the default of assignats in France in 1796 (Aubin (2008)), that a default of $\sigma$ is 
equivalent to a fourfold increase in the money growth rate in one period.

The commodity money illustrates a situation where the private agents do not trust the monetary system and therefore, only coins with intrinsic value are accepted as a medium of exchange. The gold consumption under the static state is $A_{t+1}=\delta A_{t}+A^{s}-q^{-1}(z-1) S^{s}$, thus any coinage reduces gold in utility yielding form. Here I set the coinage rate at $z=1.04$. Coins are involved with direct costs such as handling and transmission costs, and depreciation. The depreciation rate of gold coins depends on the quality of metal and minting techniques which were poor until the mechanical minting started in the 1830s. In addition, illegal activities such as clipping and shaving reduced the weight of coins, so that instead of by face value, during the historical gold standard period coins were accepted only by weight (Craig (1953)).

Given the above specifications the highest sustainable discretionary money growth rate during war is 2.30, when (55) holds with equality. As figure 2 suggests, if $d_{\text {war }} \in(1,2.30)$ the resumption of the gold standard is sustainable, and the circelled line that plots the discounted net utility of adjustment and gold standard thereafter lies above the solid line that plots default and deviation. However, if the central bank sets the money growth rate $d_{w a r}$ above 2.30 , default and the commodity money standard thereafter would yield higher utility than resumption of the gold standard.

Finally, assume that the central bank sets $d_{w a r}=2.30$. This is also the optimal sustainable money growth rate during the war because it can be shown that if there is only one war period and one adjustment period, total net utility (37) is increasing in $d_{w a r}$. Figure 3 illustrates the level of consumption and prices when the gold standard is suspended at the beginning of period 1, the economy is adjusted in period 2 and the gold standard is resumed at the beginning of period 3. As can be seen, both the price level and consumption increase during war. In the adjustment period consumption falls, because 
the price level is now below its expected level. After the resumption both the price level and consumption approach gradually their level under the gold standard. The benefit of suspension is that welfare reducing adjustment occurs during peacetime, not during war when the pressure on the government expenditure is likely to be high.

\section{Conclusions}

In this paper I reassess the suspension of the gold standard rule in the light of developments in monetary theory since Kydland and Prescott (1977). The paper models a contingent gold standard that allows for intervals during which only paper money circulates with a variable nominal price. I develop a dynamic general equilibrium model of the gold standard and the suspension, which suggests that the suspension is a credible monetary regime, because the resumption of the gold standard at the old par value in the future is a sustainable plan that replaces the gold standard as a commitment technology during war.

By building on an example first developed by Kydland and Prescott (1977), Chari and Kehoe (1990) demonstrate that the sustainable equilibrium associated with the policy plan is a sequence of history-contingent policies and allocations that are supported both by reputation and extreme trigger strategies. In my model the central bank's plan defines that after the war the monetary authority has to start adjusting the economy to the gold standard. Because the adjustment might reduce welfare temporarily, the authority has a temptation to deviate, i.e. maximize the current period's utility by printing an arbitrarily large amount of money. The outcome is deviation to a permanent static state in which paper money has lost its value and only gold specie circulates as a medium of exchange. The commodity money standard is inefficient: it does not facilitate financial intermediation, and depreciation and minting costs reduce gold available in utility yield- 
ing form. The gold standard is resumed, because it maximizes welfare in the long-run. The gold standard solves the economy's time inconsistency problem as the benevolent central bank is not able to conduct time consistent monetary policy without commitment technology in the good state of the world.

This article contributes to the understanding of a major development in monetary history, the suspension of the gold standard rule, when only inconvertible fiat paper money circulated. By some tailoring this model could be used in future research to explore individual suspension periods in detail. If the gold endowment was replaced with the competitive gold market, the model would permit analysis of the market price of gold, of which premium increased during the suspensions, but fell the end of suspension. In this model the central bank chooses the money growth rate to maximize the social welfare given the terminal condition, but Bordo and Redish (1993) and Bordo and Kydland (1996) follow the revenue-smoothing hypothesis of Mankiw (1987), and suggest that central banks suspended the gold standard to smooth public revenue from both taxes and seigniorage. Finally, the Ramsey policy in this model could be expanded to include taxation and borrowing in addition to the money growth rate to give accurate description of economic policy during the historical suspension periods.

Even though this model of sustainable plans is theoretical, it could explain broadly some key monetary developments during historical suspension periods. For example, in France in 1790, in England in 1797 and in the US in 1861 the commodity standard was suspended not just to create seigniorage but rather as an emergency measure to stabilize the circulation of paper currency. During war, or revolution in the case of France, the money stock increased steadily, but in England and the US, where the resumption of the gold standard remained credible during war, monetary authorities started to withdraw paper money from circulation immediately after the arrival of peace, and the price level fell 
respectively. By contrast, in France the revolutionary Jacobin government attempted to support the value of assignats with the laws of the Maximum which turned assignats into a guillotine-backed currency. Once Jacobin party was overthrown, controls weekended, and in 1796 after a hyperinflation the Directory demonetarized all 44 billion assignats. This model assumed that the default to resume the gold standard will destroy the credibility of monetary policy forever. In France after the default the new dictator, Napoleon Bonaparte, conducted a series of institutional changes and gave an impression that he detested the lending and paper money practices of the previous governments. According to Bordo and White (1991) his pronouncements were aimed at restoring confidence, but since the reputation of the country was destroyed, this was probably the best he could do, and he failed to secure enough funds for the disastrous Russian Campaign. England and the US, by contrast, resumed the gold standard successfully. These two countries became rivals in the financial leadership of the world and the gold standard helped them to secure real, non-inflationary growth until the First World War. (For historical accounts of these three periods, see an earlier version of this paper Newby (2008), or for example, Clapham (1944), Sargent and Velde (1995) and Friedmand and Schwartz (1963).)

Bordo and Redish (1993) argue that the gold standard survived in the nineteenth and twentieth centuries because it permitted temporary suspension of convertibility. The sustainability of the resumption plan gave the monetary authority an opportunity to conduct accommodative policies during war. Yet, to achieve this favorable position, the authority had to resist its temptation both to issue too liberally and to avoid the costly adjustment. The gold standard could only function as a contingent rule, if the resumption of the gold standard was a sustainable plan. 


\section{References}

Abreu, P., 1988. 'On the Theory of Infinitely Repeated Games with Discounting'. Econometrica 56 (2), 383-396.

Aubin, C., 2008. 'Les assignats sous la Revolution francaise: un exemple d'hyperinflation'. Revue économique 42 (4), 745-761.

Barro, R. J., 1979. 'Money and Price Level under the Gold Standard'. The Economic Journal 89 (353), 13-33.

Barro, R. J., Gordon, D. B., 1983a. 'A Positive Theory of Monetary Policy in a Natural Rate Model'. Journal of Political Economy 19 (4), 589-610.

Bordo, M., Kydland, F., 1996. 'Gold Standard as a Commitment Mechanism'. In: Bayoumi, T., Eichengreen, B., Taylor, M. (Eds.), Exchange Rate Targets and Currency Bands. Cambridge: Cambridge University Press, 55-100.

Bordo, M. D., Dittmar, R., Gavin, W. T., 2003. 'Gold, Fiat Money and Price Stability'. The Federal Reserve Bank of St. Louis Working Paper Series.

Bordo, M. D., Kydland, F. E., 1995. 'The Gold Standard as a Rule: An Essay in Exploration'. Explorations in Economic History 32, 423-464.

Bordo, M. D., Redish, A., 1993. 'Maximizing Seignorage Revenue during Temporary Suspension of Convertibility: A Note'. Oxford Economic Papers 45 (1), 157-168.

Bordo, M. D., Schwartz, A. J., 1997. 'The Specie Standard as a Contingent Rule: Some Evidence for Core and Peripheral Countries, 1880-1990'. NBER Working Papers 4860, 473-491. 
Bordo, M. D., White, E. N., 1991. 'A Tale of Two Currencies: British and French Finance During the Napoleonic Wars'. Journal of Economic History 51 (2), 303-316.

Canzoneri, M. B., Dellas, H., 1998. 'Real Interest Rates and Central Banking Operating Procedures'. Journal of Monetary Economics 42, 471-494.

Carlstrom, C. T., Fuerst, T. S., 1995. 'Interest Rate Rules vs. Money Growth Rules. A Welfare Comparision in a Cash-in-Advance Economy'. Journal of Monetary Economics $36,247-267$.

Chang, R., 1998. 'Credible Monetary Policy in an Infinite Horizon Model: Recursive Approaches'. Journal of Economic Theory 81, 431-461.

Chari, V. V., Kehoe, J., 1990. 'Sustainable Plans'. The Journal of Political Economy $98(4), 783-802$.

Clapham, J., 1944. 'The Bank of England. A History'. Cambridge: Cambridge University Press, (2 Volumes).

Craig, J., 1953. 'The Mint. A History of the London Mint from A.D.287 to 1948'. Cambridge: Cambridge University Press.

Duffy, I. P. H., 1982. 'The Discount Policy of the Bank of England During the Suspension of Cash Payments, 1797-1821'. Economic History Review 35 (1), 67-82.

Feavearyear, A., 1963. 'The Pound Sterling. A History of English Money'. Oxford: Oxford University Press, 2nd edition.

Friedmand, M., Schwartz, A. J., 1963. 'A Monetary History of the United States 18671960', 7th Edition. Princeton: Princeton University Press. 
Goodfriend, M., 1988. 'Central Banking under the Gold Standard'. Carnegie-Rochester Conference Series on Public Policy 29, 85-124.

Grossman, H. I., Van Huyck, J. B., 1988. 'Sovereign Debt as a Contingent Claim: Excusable Default, Repudiation and Reputation'. American Economic Review 78, 1088-1097.

Hanes, C., 1993. 'The Development of Nominal Wage Rigidity in the Late 19th Century'. The American Economic Review 83 (4), 732-756.

Ireland, P., 1997. 'Sustainable Monetary Policies'. Journal of Economic Dynamics and Control 22, 87-108.

Kydland, F., Prescott, E., 1977. 'Rules rather than discretion: The inconsistency of optimal plans'. Journal of Political Economy 85, 473-491.

Lindert, P., Williamson, J. G., 1984. 'English Workers' Living Standards during the Industrial Revolutions: A New Look'. Economic History Review 36 (1), 1-25.

Mankiw, N. G., 1987. 'The Optimal Collection of Seignorage'. Journal of Monetary Economy $20,327-341$.

Newby, E., 2008. 'The Suspension of the Gold Standard as a Sustainable Plan'. Cambridge working papers in economics (0856).

Ricardo, D., 1821. 'On The Principles of Political Economy and Taxation'. London: John Murray.

Santoni, G. J., 1984. 'A Private Central Bank: Some Olde English Lessons'. Federal Reserve Bank of St Louis.

Sargent, T. J., Velde, F. R., 1995. 'Macroeconomic Features of the French Revolution'. Journal of Political Economy 103 (4), 474-516. 
Sargent, T. J., Wallace, N., 1983. 'A Model of Commodity Money'. Journal of Monetary Economics 12, 163-187.

Schmitt-Grohe, S., Uribe, M., 2000. 'Price Level Determinacy and Monetary Policy under a Balanced-budget Requirement'. Journal of Monetary Economy 45, 211-246.

Stokey, N. L., 1989. 'Reputation and Time Consistency'. The American Economic Review $2,134-139$.

Velde, F. R., Weber, W. E., 2000. 'A Model of Bimetalism'. The Journal of Political Economy 108 (6), 1210-1234. 


\section{Appendix A}

Equilibrium under the gold standard The household maximizes (16) subject to constraints (17), (18) and (27) for all $t=0,1,2, \ldots$, taking $A^{s}, p_{t}, R, \pi_{t}^{f}, \pi_{t}^{c}$ and $w_{t}$ given for all $t=0,1,2, \ldots$. The Lagrangian becomes

$$
\begin{aligned}
\mathcal{L}= & \sum_{t=0}^{\infty} \beta^{t}\left\{\left[u\left(C_{t}\right)+\rho v\left(A_{t+1}\right)\right]\right. \\
& +\lambda_{t}\left[m_{t}+q \delta S_{t}+\delta q A_{t}+q A^{s}+w_{t} L_{t}+\pi_{t}^{f}+\pi_{t}^{c}-p_{t} C_{t}-q A_{t}-\hat{t}_{t}-d_{t} x_{t} m_{t+1}+q S_{t+1}-q A_{t+1}\right] \\
& +\mu_{t}\left[m_{t}+q \delta S_{t}+\left(x_{t}-1\right) \eta_{t} m^{s}+q(1-\phi)\left(z_{t}-1\right) S_{t}^{s}+w_{t} L_{t}-p_{t} C_{t}\right] \\
& \left.+\zeta_{t}\left[q\left(A^{s}+\delta A_{t}\right)-q\left(z_{t}-1\right) S_{t}^{s}-\left(x_{t}-1\right) \eta_{t} m_{t}^{s}-q A_{t+1}\right]\right\}
\end{aligned}
$$

where $\lambda_{t}, \mu_{t}$ and $\zeta_{t}$ are Lagrangian multipliers on the budget, cash-in-advance and gold endowment constraints. The first order conditions are

$$
\begin{array}{rll}
C_{t} & : \quad u_{C}(t)=p_{t}\left(\lambda_{t}+\mu_{t}\right) \\
A_{t}: & q\left(\lambda_{t}+\zeta_{t}\right)=\rho v_{A}(t+1)+\delta \beta q\left(\lambda_{t+1}+\zeta_{t+1}\right) \\
m_{t+1}: & d_{t} x_{t} \lambda_{t}=\beta\left(\lambda_{t+1}+\mu_{t+1}\right) \\
m_{t}^{s}: & \mu_{t}=\zeta_{t} \\
S_{t+1} & : \quad \lambda_{t}=\delta \beta\left(\lambda_{t+1}+\mu_{t+1}\right) \\
S_{t}^{s} & : \quad \mu_{t}(1-\phi)=\zeta_{t}
\end{array}
$$

and

$$
\begin{aligned}
& \lim _{t \rightarrow \infty} \beta^{t}\left(\lambda_{t}+\mu_{t}\right) A_{t}=0 \\
& \lim _{t \rightarrow \infty} \beta^{t}\left(\lambda_{t}+\mu_{t}\right) m_{t}=0 \\
& \lim _{t \rightarrow \infty} \beta^{t} \delta\left(\lambda_{t}+\mu_{t}\right) S_{t}=0 .
\end{aligned}
$$

By defining $m_{0}=S_{0}=1$ and using market clearing conditions (22)-(24), and (25) and (26), the cash-in-advance constraint can be written as (29). 
By writing $C_{t}=Y_{t}-G_{t}$ and substituting normalized (13) and (25) into the left-handside of (17), reorganizing, and writing this for $p_{t}$ gives

$$
p_{t}=\omega_{t}^{\gamma}\left\{1+q \delta+q(1-\phi)\left(z_{t}-1\right)-\eta+d_{t} x_{t}\right\}^{1-\gamma}
$$

and substituting this back to (29) gives

$$
C_{t}=\omega_{t}^{-\gamma}\left\{1+q \delta+q(1-\phi)\left(z_{t}-1\right)-\eta+d_{t} x_{t}\right\}^{\gamma}-G_{t}
$$

Proof of Proposition 1 In a gold standard equilibrium with constant $\eta$ the central bank commits to a policy $\left\{d_{t}=1 \mid t=0,1,2, \ldots\right\}$. As a result $d_{t}=1$ in the above Lagrangian and first order conditions. In equilibrium (see proposition 2) the expected price level $\omega_{t}$ must equal the actual price level $p_{t}$, which becomes

$$
p_{t}=\left\{1+q \delta+q(1-\phi)\left(z_{t}-1\right)-\eta+x_{t}\right\} \text { for all } t=0,1,2, \ldots
$$

If $\omega_{t}=p_{t}$, from (13) $Y_{t}=1$ and the household's consumption simplifies to $C_{t}=1-G_{t}$, thus in equilibrium consumption is independent of $x_{t}$ or $z_{t}$. However, in equilibrium the gold consumption is a decreasing function of $x_{t}$ and $z_{t}$, because taking gold to the central bank or coinage reduce gold available in consumable form. The private gold consumption is

$$
A_{t+1}=\delta A_{t}+A^{s}-\left(z_{t}-1\right) S_{t}^{s}-\frac{x_{t}-1}{q} \eta
$$

where $x_{t} \in(\beta, \bar{x}), \bar{x}=1+q \frac{\delta A_{t}+A^{s}}{\eta}$ and $z_{t} \in(1, \bar{z}), \bar{z}=1+\delta A_{t}+A^{s}$. Therefore, as long as $x_{t} \in(\beta, 1)$ using only paper currency as a medium of exchange yields at least as high utility than using both paper currency and coins, or only coins, as a medium of exchange. In the gold standard equilibrium with a constant $\eta$ the household utility is maximized when $z_{t}=1$ and $x_{t}=\beta$ for all $t=0,1,2, \ldots$ 


\section{Appendix B}

The terminal condition states that when the gold standard is resumed, money must be proportional to gold stock

$$
M_{\tau+S+1}=\frac{Q A_{\tau+S+1}^{g}}{\eta}
$$

By substituting the left-hand-side by $x_{\tau+S} d_{\tau+S} M_{\tau+S}=M_{\tau+S+1}$ and writing the righthand-side by using

$$
A_{\tau+i+1}^{g}-A_{\tau+i}^{g}=\delta A_{\tau+i}+A_{\tau+i}^{s}-A_{\tau+i+1}
$$

we get

$$
x_{\tau+S} d_{\tau+S} \eta M_{\tau+S}=Q A_{\tau+S}^{g}+Q\left(\delta A_{\tau+S}+A_{\tau+S}^{s}-A_{\tau+S+1}\right)
$$

Continuing this recursively backwards until the beginning of the suspension and recognizing that the gold flow resumes at period $\tau+j$ we get that

$$
x_{\tau} d_{\tau} \ldots x_{\tau+S-1} d_{\tau+S-1} x_{\tau+S} d_{\tau+S} \eta M_{\tau}=Q A_{\tau}^{g}+Q \sum_{i=j}^{S}\left(\delta A_{\tau+i}+A_{\tau+i}^{s}-A_{\tau+i+1}\right) .
$$

By writing $Q A_{\tau}^{g}=\eta M_{\tau}$ and reorganizing we get

$$
\left(\prod_{i=0}^{S} x_{\tau+i} d_{\tau+i}-1\right) \eta M_{\tau}=Q \sum_{i=j}^{S}\left(\delta A_{\tau+i}+A_{\tau+i}^{s}-A_{\tau+i+1}\right) .
$$

If (C1) is scaled by $M^{s}$ we have (43). 


\section{Figures}

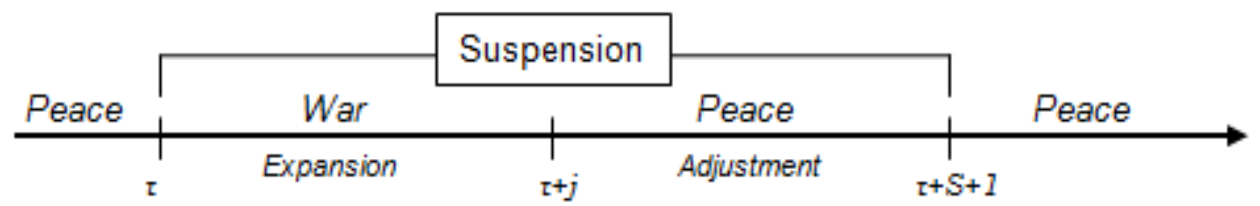

Figure 1: The timeline of a suspension 


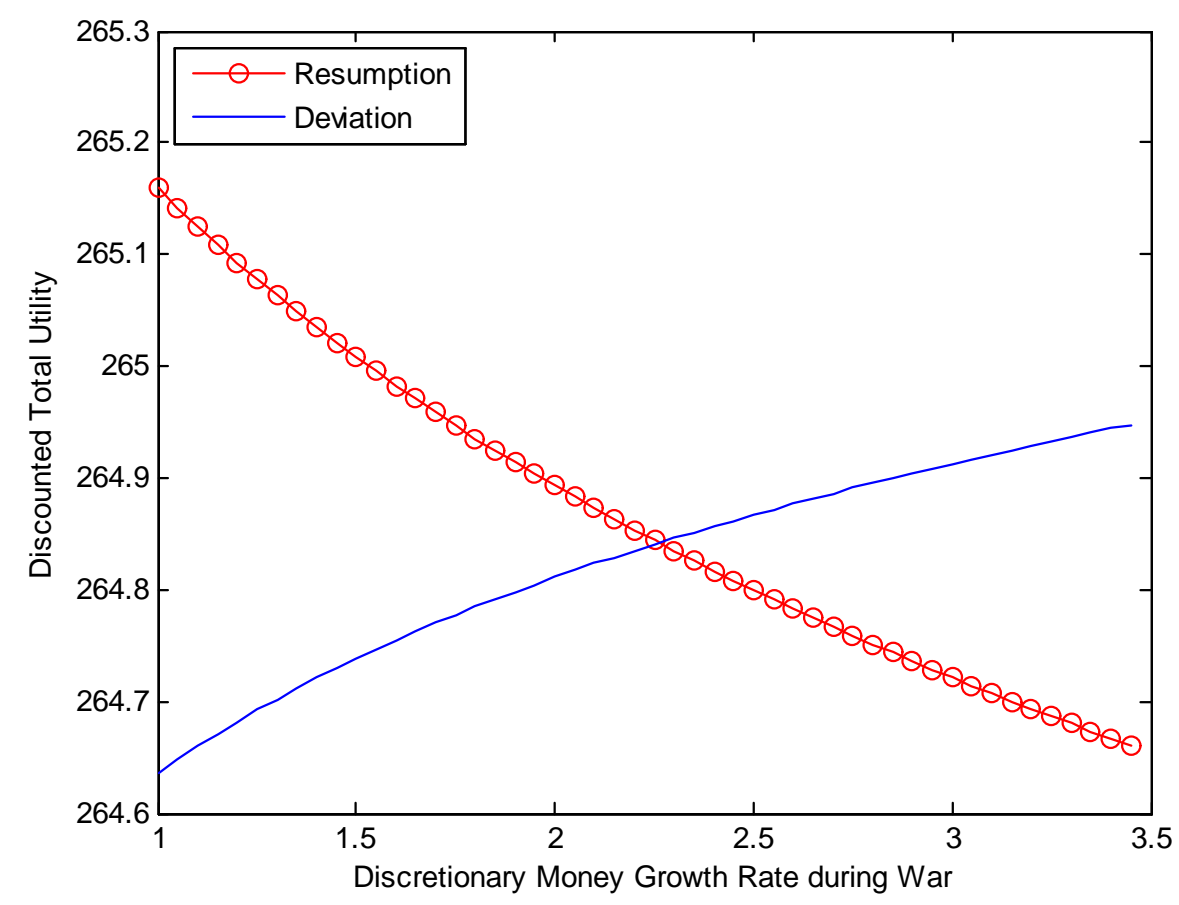

Figure 2: Discounted net utilities of the resumption of the gold standard and default
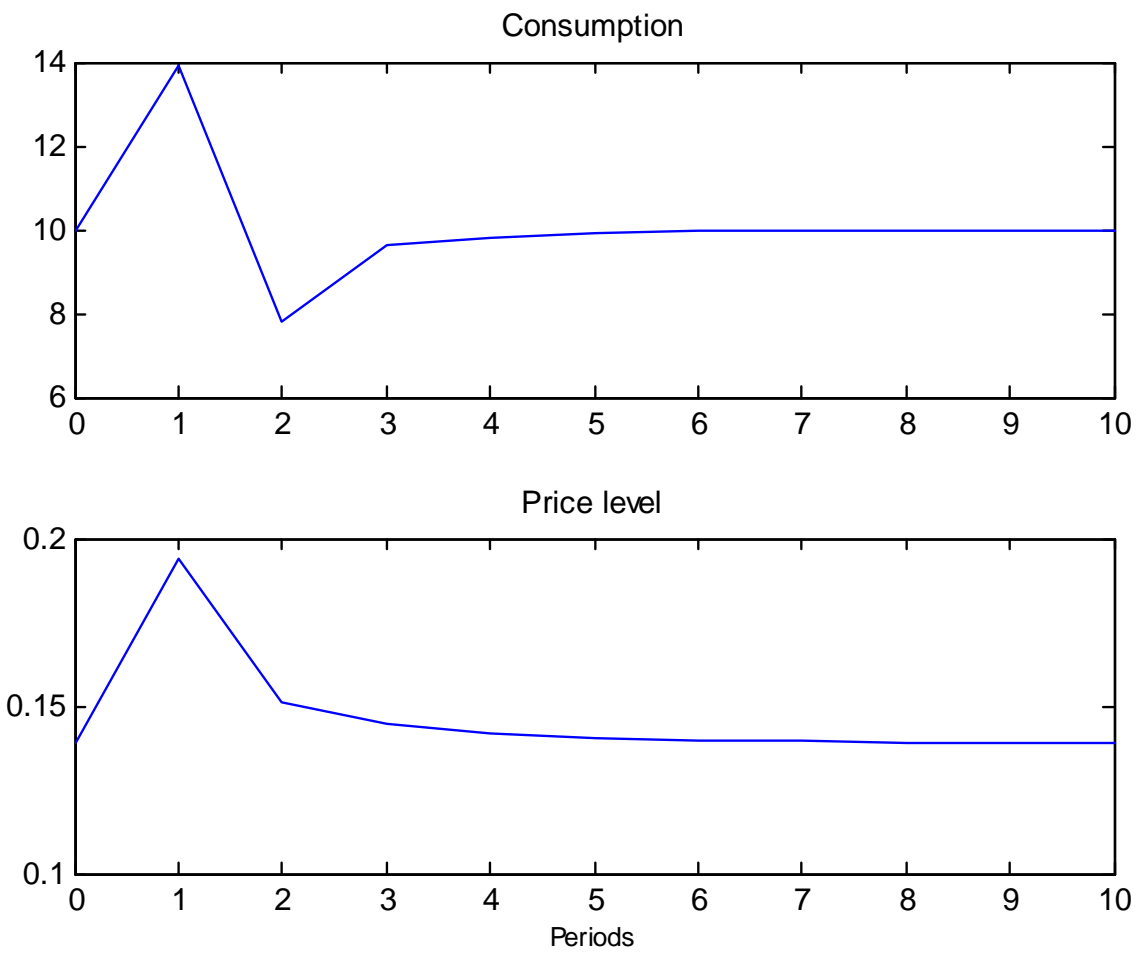

Figure 3: Consumption and price level under war (period 1) and adjustment (period 2) 